\title{
Effect of Heavy Metal Stress on Antioxidase Enzymes
}

\author{
Hua Lin ${ }^{1,2 a}$, Ya-li Peng ${ }^{1 b}$, Jun Chen ${ }^{1,2 c^{*}}$, Liang Liang ${ }^{1 d}$ \\ 1 College of Environmental Science and Engineering, Guilin University of Technology, Guilin \\ 541004; 2 Guangxi Scientific Experiment Center of Mining, Metallurgy and Environment, Guilin \\ University of Technology, Guilin 541004 \\ aemail: linhua5894@163.com; bemail: 1158499438@qq.com; 'email: \\ chenjun1104@126.com( Corresponding author); 'email: 490747082@qq.com
}

Key Words:Heavy Metal Pollution; reactive oxygen species; antioxidant system

\begin{abstract}
This article discusses the role of reactive oxygen species in plants,composition of antioxidant system,composition and role of antioxidant enzymes, and effect of heavy metals stress on the individual antioxidant enzymes activity.Under normal circumstances, in plants bodies, reactive oxygen species production and clear (antioxidant system) is in a dynamic equilibrium,But when this balance is broken,the plants get accumulation of reactive oxygen species, and that would harm the growth of plants.
\end{abstract}

\section{Introduction}

According to statistics, China's arable land polluted by heavy-metal contamination up to $20,000,000 \mathrm{hm}^{2}$, heavy-metal contamination of food each year up to $12,000,000 \mathrm{t}^{[1]}$.So with heavy metal pollution is worsening, people generated a great deal of attention to this ${ }^{[2]}$.heavy metal is highly toxic which can not be biodegradable, it can produce oxidative damage to plants, even cause plant death by the intermediary role of reactive oxygen species and so on ${ }^{[3-7]}$. Many studies show that $\mathrm{Cd}, \mathrm{Pb}$ and other heavy metals can have an impact on these normal physiological metabolism,including respiration, photosynthesis and plant nutrition metabolism, thus the result affect the growth and development of plants, inhibiting their growth and developent ${ }^{[1]}$. Rong-chun Li believed that inhibition of growth caused by heavy-metal contamination related to metabolism of reactive oxygen species which effects plant body ${ }^{[8]}$. Heavy metals, drought, lack of nutrition, air pollution and other adverse conditions may lead to radical increase in plant cells and free radical scavenging capacity change ${ }^{[9-12]}$. To this end, for these stress conditions, plant accordingly opened a series of complex antioxidant enzyme systems and non-antioxidant system ${ }^{[13]}$.

Oxygen is substances required by plants for normal plant growth, metabolism and other life activities .Oxygen will be converted to superoxide anion $\left(\mathrm{O}_{2}{ }^{-}\right)$, hydrogen peroxide $\left(\mathrm{H}_{2} \mathrm{O}_{2}\right)$, singlet oxygen $\left({ }^{1} \mathrm{O}_{2}\right)$ and hydroxyl radical $(\cdot \mathrm{OH})$ and other toxic substances to plants in the process of the plant's own metabolism, which are called reactive oxygen species(AOS).In plants, reactive oxygen accumulation cause a significant increase to lipoperoxide,resulting in destruction of the cell membrane structure ${ }^{[14]}$.If the active oxygen can not be promptly cleared in plants, it will produce toxic effects on plants, so that plants can not grow normally.Plant in order to maintain normal life activities, which itself has the ability to resisting and scavenging reactive oxygen species.Under normal physiological conditions, in the synergistic effect of the enzymatic and non-enzymatic antioxidant systems in plants, plants can scavenge reactive oxygen species (AOS) generated continuously ${ }^{[15]}$.This action make reactive oxygen species (AOS) generation and eliminate in dynamic equilibrium, reactive oxygen species (AOS) is maintained at a very low harmless levels to 
normal life activities of plants .

\section{Antioxidant system of plants}

Antioxidant system is consisted of two main parts, namely antioxidant enzymes and antioxidants category. These synergy of two parts can remove oxygen inside plant cells. The main antioxidant enzymes include superoxide dismutase (SOD), peroxidase (POD), catalase (CAT) and other enzymes.

\section{superoxide dismutase(SOD)}

superoxide dismutase is widely present in all aerobic organisms, is the first enzyme substance of free radical scavenging in vivo, but also is a the active substance from living body[ ${ }^{16]}$. SOD will catalyze the decomposition of superoxide anion into radical oxygen $\left(\mathrm{O}_{2}\right)$ and hydrogen peroxide $\left(\mathrm{H}_{2} \mathrm{O}_{2}\right)$, and further converted to ground-state oxygen $\left(\mathrm{O}_{2}\right)$ and water $\left(\mathrm{H}_{2} \mathrm{O}\right)$. Usually depending on the metal cofactors, SOD can be divided into three isoenzymes. The fist is $\mathrm{Cu} / \mathrm{Zn}-\mathrm{SOD}$ existing in eukaryotic cell cytoplasm, the second is Mn-SOD existing in prokaryocyte and eukaryotic cells mitochondria and the third is Fe-SOD existing in prokaryocyte ${ }^{[17]}$. SOD exists mainly in Cytoplasm, followed by mitochondria.Therefore, different parts of the plant cells have the antioxidant capacity.

Under normal circumstances,chloroplasts and mitochondria existing in plant cell in the photosynthesis and respiration produce $\mathrm{O}_{2}{ }^{-}$, SOD will convert $\mathrm{O}_{2}{ }^{-}$into $\mathrm{H}_{2} \mathrm{O}_{2}$ and $\mathrm{O}_{2}$ by disproportionation, and accordingly scavenge $\mathrm{O}_{2}{ }^{-}$, finally reduce membrane lipid peroxidation.Under adverse conditions, a certain degree of $\mathrm{O}_{2}{ }^{-}$increase make SOD activity improve and maintain the ability to remove free radicals to protect cells from and to resist the toxic effects of adversity from the outside environment.YAN Yan et al. ${ }^{[18]}$ studied Leersia hexandra Swartz response to chromium-induced oxidative stress, the results showed that with the $\mathrm{Cr}^{3+}, \mathrm{Cr}^{6+}$ concentration (0-60mg / L) increased ,the Leersia hexandra Swartz seedling leaves, stems, roots of SOD activity in the $\mathrm{Cr}^{3+}$ concentration showed a gradual upward trend; SOD activity showed increased at firs upward then decreased trend in the $\mathrm{Cr}^{6+}$ concentration , and there was a peak at $20 \mathrm{mg} / \mathrm{L}$. When active oxygen was gradually increased over the normal disproportionation ability, functional intracellular enzymes and membrane system inside cells wouldl damage, this would lead to plant physiological dysfunction, and maked the SOD activity decreased.Because the difference of root morphology, growth, distribution and the different distribution of SOD isozymes in plant organs caused a degree of Leersia hexandra Swartz sensitivity to $\mathrm{Cr}^{6+}$ concentration: $r o o t>$ leaf $>$ stem. GE Cai-lin et al ${ }^{[19]}$ with different concentrations of $\mathrm{Cd}^{2+}, \mathrm{Cu}^{2+}$ and $\mathrm{Hg}^{2+}$ studied flowering rice change of SOD activity.the results of study suggested that the order of rice SOD activity: leaves> panicle> root,and increasing the concentration of cadmium inhibited the SOD activity of rice roots, the degree of inhibition was positively correlated with the concentration of cadmium;but SOD activity to panicles and leaves related to rice varieties.GAO Yang ${ }^{[20]}$ stuied antioxidative defense system differences among four plants under combined $\mathrm{Pb}$ and $\mathrm{Cd}$ stress.the studies suggested that the hyperaccumulative plants of Solanum nigrum and Brassica juncea,their superoxide dismutase (SOD) activity increased with increasing concentration of heavy metals in the soil.Sensitivity of Brassica juncea's SOD activity reaction was higher than Solanum nigrum's , and indicated the non-hyperaccumulative plants of maize's (Zea mays) presents no regularity; radish's (Raphanus sativus) SOD activity with change of heavy metals concentrations did not change significantly, and its SOD activity was lower than other plants' .Hyperaccumulators' SOD activity under combined $\mathrm{Pb}$ and $\mathrm{Cd}$ stress significantly correlated with to heavy metal toxicity coefficient in soil ,the maize'(Zea mays) correlation was not obvious, and radishe' s(Raphanus sativus) almost unchanged. XIE Fei ${ }^{[21]}$, his studies showd that after arsenic (As) stress on arsenic hyperaccumulator 
plant of Pteris cretica var.nervosa and non-arsenic hyperaccumulator plant of Pteris ensiformis ,the former had high SOD activity and a better antioxidant capacity than the latter.this indicated that the role of SOD in hyperaccumulator antioxidant defense was more significant.

\section{Peroxidase (POD)}

Peroxidase (POD) which has heme is oxidoreductase.It has important physiological functions, such as participation in plant photosynthesis, respiration, formation of lignin, auxin metabolism, trauma healing and virus resistance, etc.Peroxidase is enzymatic protection system to scavenging reactive oxygen species.Peroxidase plays an important role in scavenging oxygen free radicals, resisingt membrane lipid peroxidation and protecting cell membranes, and peroxidase can be used as a sign of plant senescence ${ }^{[22]}$.Peroxidase's main function is to redox hydrogen peroxide $\left(\mathrm{H}_{2} \mathrm{O}_{2}\right)$ into water $\left(\mathrm{H}_{2} \mathrm{O}\right)$ and oxygen $\left(\mathrm{O}_{2}\right)$

When heavy metals stress on the plants, in order to resist external stress environment, plants's SOD activity increase remove large amounts of reactive oxygen species. POD clears $\mathrm{H}_{2} \mathrm{O}_{2}$ produced by SOD catalyzes superoxide anion.POD activity in the adversity stress condition changes. ZHANG Tai-ping et $\mathrm{al}^{[23]}$ studied reaction of peroxidase of maize (Zea mays L.) from heavy-metal polluted environment to the stress of $\mathrm{Pb}^{2+}$.the studies suggested that POD activity of maize samples from heavy metal polluted environment was higher than that from clear environment;and the planting time was longer continuous, POD activity showed increasing trend.ZHANG Xue-hong et al ${ }^{[24]}$, s studies to Leersia hexandra Swartz showed that POD activity increased with the increase of chromium concentration,the trend was increased at first and then decreased; and the result was consistent with Yan Yan et $\mathrm{al}^{[18]}$ studied conclusion to chromium stress on Leersia hexandra Swartz and Jia-hong ZHAN Jia-hong et al $^{[25]}$ studied impact of mercury pollution to rice seedlings growth and peroxidase activity; and POD activity was more sensitive to $\mathrm{Cr}^{6+}$ relative to $\mathrm{Cr}^{3+}$, the degree of sensibility:stem> leaf> root.This might be related with POD function no specificity and POD enzyme distribution in different organs,content, expressiveness ${ }^{[26]}$. GAO Yang et al ${ }^{[20]}$ showed that since POD functional diversity,there was a more significant between POD activity of non-hyperaccumulator plants of maize (Zea mays L.) and radish (Raphanus sativus) and heavy metal toxicity coefficient. XIE Kai-bin et $\mathrm{al}^{[27]}$ stuied the effects of $\mathrm{Hg}^{2+}$ pollution on activity of peroxidase in and Trapa bicornis $\mathbf{O}$ sbeck the results suggested that POD activity of roots of Euryale ferox Salisb decreased with the concentration of $\mathrm{Hg}^{2+}$ increase, and with timeof $\mathrm{Hg}^{2+}$ stress was longer, all POD activity became a downward trend under different concentration of $\mathrm{Hg}^{2+}$; After different concentration of $\mathrm{Hg}^{2+}(5-30 \mathrm{mg} / \mathrm{L})$ stress 24 hours, anzyme activity increased with the concentration increase and decreased with concentration of $\mathrm{Hg}^{2+}(30-40 \mathrm{mg} / \mathrm{L})$ increase;But after stress 48,72,96 hours, anzyme activity decreased with concentration increase.Low concentrations of heavy metals and short-term stress stimulated hydrogen peroxide increase $\left(\mathrm{H}_{2} \mathrm{O}_{2}\right)$ in plants, this promoted POD to catalyze excessive hydrogen peroxide, so that POD activity increased.But with the concentration increase and prolonged stress, the increase of hydrogen peroxide content in plants and heavy metals maked activity decreased and enzyme protein poisoned,this gradually caused enzyme inactivation.

\section{Caatlase ( CAT )}

Catalase (Caatlase, CAT) is tetrameric enzyme having heme and commonly found in all organizations of plants comprising enzyme tetramer.It is terminal of a series of antioxidant enzymes in biological oxidation.It exists primarily microbodies (peroxisomes, glyoxysomes and related oxidase targeted organelles).Its main role is to make hydrogen peroxide form water and oxygen by disproportionation.Because of the high $\mathrm{Km}$ value of the reaction, so the reaction requires high CAT concentration. CAT's main function is to remove hydrogen peroxide produced by photorespiration in leaves ${ }^{[28]}$.Since CAT assistant agent is a photosensitizer, light make CAT inactivation. The inactivation of Leaf cells's peroxisome like that. In the chloroplasts, CAT remove hydrogen peroxide by catalase's catalytic reaction, but it is not involved in the decomposition process of 
hydrogen peroxide.Catalase's management functions mainly include: stress-resistance signal factors of plants, regulation of apoptosis factor, maintaining plant cells's oxidation - reduction dynamic equilibrium, etc ${ }^{[29]}$.

CAT is a kind of eco-protective enzymes, under the action of stress factor, biological organism through its own mechanism of enzyme can make the plant itself produce protective reaction to toxicant which can produce toxicity to plant itself. CAT activity changes can be used indicators to an adverse environmental factors of biological damage.LI Yan et al ${ }^{[30]}$ studied the effect of different Mn concentrations $(0,0.5,1,2,4,8 \mathrm{nmol} / \mathrm{L})$ on antioxidant mechanism of hyperaccumulator Polygonum pubescens Blume which was a newly Mn hyperaccumulator. The result showed that in the leaves of Polygonum pubescens Blume, CAT activity showed a trend of increase first and then decline, and CAT activity reached the maximum when Mn stress concentration was at $2 \mathrm{nmol} / \mathrm{L}$. ZHU Qi-hong et al ${ }^{[31]}$ studied the effect of lead $\left(\mathrm{Pb}^{2+}\right)$ stress on Pteris vittata. The studied suggested that with $\mathrm{Pb}$ concentration $(0,500,1000,1500,2000,2500 \mathrm{mg} / \mathrm{L})$ increase, CAT activity at first increased and then decline, and CAT activity reached the maximum when $\mathrm{Pb}$ stress concentration was at $100 \mathrm{mgl} / \mathrm{L}$. The reason might be that under the low concentration of heavy metal stress, plant was stimulated by adversity factors, its active oxygen in the body increased, and this prompted SOD activity increase, disproportionation reaction produced excessive $\mathrm{H}_{2} \mathrm{O}_{2}$, Caatlase maked stress response to $\mathrm{H}_{2} \mathrm{O}_{2}$ so that its activity increased. With the increase of stress factor concentration, the accumulation of active oxygen in the body was beyond the adjustment ability of enzymes in plant body, thus this inhibited the CAT activity, so that the CAT activity declined.Heavy metal stress time to plants also have an impact on CAT activity. TANG Chun-fang et $\mathrm{al}^{[32]}$ studied effect of heavy-metal Cadmium stress on CAT activity of seedlings of radish. The resullts suggested that under three different $\mathrm{Cd}^{2+}$ concentrations $(0,250,500 \mathrm{umol} / \mathrm{L})$, leaives's CAT activity of seedling within 100 hours with the extension of stress time presented a trend of at first increase and then decline; Roots's CAT activity showed a downward and then slightly rebounded trend. XIE Fei et $\mathrm{al}^{[21]}$ their Research also confirmed that the heavy metal stress time also had an impact on CAT activity. Different stress factors would produce different effects on CAT activity of the same plant. GE Cai-lin et $\mathrm{al}^{[33]}$ studied the effect of three kinds of heavy metal stress on CAT activity of Oryza sativa L.The results showed that for Wuyujing seedling, Yangdao 6 seedling, Shanyou 818 seedling, Stress concentration of heavy metals in the $0.05 \sim 2.0 \mathrm{mM}$, CAT activity in leaves continued to decline with the concentration of $\mathrm{Cu}$ and $\mathrm{Cd}$ increase, CAT activity showed a downward trend at first with $\mathrm{Hg}$ concentrations increase and then slight increase and then significant decline.There were significant differences for inhibition degree of different heavy metals to leaves's CAT activity of tested rice varieties. Cu stress on inhibition of CAT activity was clearly greater than Cd stress, and significantly greater than $\mathrm{Hg}$ stress .

\section{Conclusion}

Under normal physiological metabolism, production and scavenging of plant their bodies's reactive oxygen species is in dynamic equilibrium state.Oxidation system is so vital to the survival of plants to the environment under normal circumstances.But in some severe cases, such as drought, high temperature, low temperature, water stress, salt stress, heavy metal pollution, etc, dynamic equilibrium will be broken, leading to accumulation of reactive oxygen species in vivo, resulting in active oxygen damage to the plant cells (Membrane lipid peroxidation and lipid peroxidation), aldehyde effect formed by oxidation reaction, hydroxyl radicals effect and Hydroperoxide effect. When heavy metal stress over defense system of plants, active oxygen content in the body will be beyond the amount of demand for disproportionation under normal circumstances, this will 
inevitably lead to the whole plant physiological processes disorder, plant growth is affected, such as seed germination, vegetative growth, plant development ,etc. Therefore, to improve plant resistance is crucial (increasing the activity of antioxidant enzymes in plants and enhancing the level of antioxidant metabolism can improve the resistance of plants. Clarifying the mechanism of plant resistance to heavy metals, and further exploring the key factors controlling heavy metal damage and resistance are the focus of future research,in order to provide important basis for the plants's antioxidant gene research and the breeding of transgenic plants.

\section{Acknowledgements}

This work was supported by the Natural Science Foundation of China (No. 41361085), Special Funding for Guangxi Bagui Scholars Construction Projects, Guangxi Graduate Education Innovation Project and the Guangxi Talent Highland for Hazardous Waste Disposal Industrialization.

\section{References}

[1]CHEN Lili ,E Shengzhe . Current situation of soil contamination by heavy metals and research advandces on the bioremediation techniques in China [J]. Modern Agricultural Sciences, 2009,16(3).

[2]CHEN Tongbin,HUANG Qifei,GAO Ding, et al. Heavy metal concentrations and their decreasing trends in sewage sludges of China [J] . Acta Scientiae Circumstantiae, 2003,23(5). [3]Chaoui A,Mazhoudi S,Ghorbal M H,Ferjani E E.Cadmium and zinc induction of lipid peroxidation and effcets on antioxidant enzyme activities in bean.Plant Sei,1997,127:139-147

[4]Shah K,Kumar R G,Verma A,Dubey R S.Eeffet of cadmium on lipid peroxidation,superoxide naion generation and aetivitivies of antioxidant enzymes in growing rice seedlings .Plant Sei,2001,161:1135-1144

[5]Gallego S M,Benavides M P,Tomaro M L.Eeffets of heavy lion exeess on sunflower leaves:evidence for involvement of oxidative stress.Plant Sei,1996,121:151-159

[6]Malecka A,Jarmuszkiewicz W,Tomaszewska B.Antioxidative defense to lead stress in subcellular compartments of pea root cells.Acta Bioehim Polon,2001,48(3):687 - 698

[7]Cho U H,Park J O.Mercury-induced oxidative stress in tomato seedlings.Plant Sei,2000,156:1-9 [8]SHAOGuo-sheng,Muhammad J H,ZHANGXiu-fu,et al. effects of cadmium stress on plant growth and antioxidative enzyme system in different rice genotypes. Chinese J Rice Sci, 2004,18(3):239-244.

[9]QIANG W ei-ya1,HOU Jiu-ju,YANG Hui, et,al. Studying on effect of Cd in combination with UV-B on physiological mechanism in regulation of soybean epicotyl growth. Acta Bot.Boreal.-Occident.Sin, 2005, 25(1): 0082-0087.

[10]Mittler R,Zilinskas B A.Regulation of pea cytosolic ascorbate peroxidase and other antioxidant enzymes during the progression of drought stress and following recovery from drought. The Plant Journal,1994,4,5:397-405

[11]Lin $\mathrm{C}$ C,Kao $\mathrm{C}$ H.Effect of $\mathrm{Nacl}$ stress on $\mathrm{H}_{2} \mathrm{O}_{2}$ metabolism in rice leaves. Plant Growth Regulation,2000,30:151-155

[12]Noetor Q,Foyer C H .Asorbate and glutathione:keeping active oxygen under control. Annual Review of Plant Biology,1998,49:249-279

[13]ZHAO Hui,ZHANG Hai-yan. Effects on the activities of non-enzymatic system and antioxidant system in leaves of Sorghum Hybrid sudangrass seedlings under $\mathrm{Cr}^{6+}$ stress. Journal of Beijing Union University,2013,27(3).

[14]Mishra N P, Misha R K, Singlral G S. Changes in the activities of anti-oxidant enzymes during exposure on intact wheat leaves to strong visible light at different temperatures in the preasence of 
protein synthesis inhibitors[J]. Plant Physiology, 1993, 102:903-910.

[15]Xue Xin,Zhang Qian,Wu Jin-xia.Research of reactive oxygen species in plants and its application on stress tolerance.Biotechnology Bulletin,2013(10).

[16]SUN Cheng-fen,MA Li,SHENG Lian-xi,et al.Soil naphthaline pollution stress on corn (Zea mays L.) seedling pjysiological effect.Journal of Agro-Environment Science,2009,28(3):443-448.

[17]TIAN Chun-mei,ZHONG Qiu-ping. Advance in current research of superoxide dismutase. China Tropical Medicine,2005,5(8).

[18]YAN Yan,LI Jian-ping,ZHANG Xue-hong. Response of hyperaccumulator Leersia hexandra Swart to chromium-induced oxidative stress. Ecology and Environment,2008, 17(4): 1476-1482.

[19]GE Cai-lin,YANG Xiao-yong,JIN Yang, et al. Effect of heavy metal stress on different rice varieties of superoxide dismutase.Acta Agriculturae Nucleatae Sinica,2003,17(4):286-291.

[20]GAO Yang, MAO Liang ,ZHOU Pei.et al. Antioxidative defense system differences among four plants under combined $\mathrm{Pb}$ and $\mathrm{Cd}$ stress.Chinese Journal of Eco-Agriculture, July 2010, 18(4): 836-842.

[21]XIE Fei,WANG Hong-bin,WANG Hai-jian, et al. Effects of arsenic on activities of antioxidant enzymes in the fronds of plants with different abilities to accumulate arsenic. Journal of Agro-Environment Science,2009,28(7):1379-1385.

[22]Zhang J X, Kirkham M B . Drought-stress-induced changes in activities of superoxide dismutase, catalase, and peroxidase in wheat species [J]. Plant Cell Physiol,1994,35(5):785-791.

[23]ZHANG Tai-paing,PAN Wei-pin. Response of $\mathrm{Pb}^{2+}$ stress on Zea mays L. from heavy metal pollution of environment. Journal of South China University of Technology(Natural Science Edition),February 2003,31(2).

[24]ZHANG Xue-hong,LIU Jie,ZHU Yi-nian. Research of phytoremediation of heavy metal contaminated soil[M].Science Press,June 2011.

[25]ZHAN Jia-hong,LAN Zong-hui,CHEN Jie-feng. Impact of mercury-polluted rice seedling growth and its peroxidase activity.Tournal of Hanshan Normal University,june 2007,28(3).

[26]ZHU Hong-xia,YANG Xiao-yong,GE Cai-lin, et al. Effect of heavy metals on the peroxidase isoenzymes in rice. Acta Agriculturae Nucleatae Sinica,2004,18(3):233-236.

[27]XIE Kai-bin,SHI Guo-xin,CHEN guo-xian, et al. The effects of $\mathrm{Hg}^{2+}$ pollution on activity of peroxidase in roots of Euryale ferox salisb and Trapa bicorn is o sbeck. Journal of Wuhan Botanical Research,2000, 18(1): 70-72.

[28]willekens H,Inze D,van Montagu M.Catalases in plants[J].Molecular Breeding,1995,1:207-208. [29]NAN Rui-zhi,FAN Yue-xian. Advance of researches on catalase in plants. Anhui Agri Sci Bull,2008,14(5).

[30]LI Yan,LIU Ke-hui,YU Fang-ming, et al. Effects of manganesee on enzymatic and non-enzymatic antioxidative defenses of the hyperaccumulate Ploygonum pubescens Blume. Journal of Agro-Environment Science,2011,30(12):2422-2427.

[31]ZHU Qi-hong,XIA Hong-xia. Effects of lead stress on antioxidant enzyme system and chlorophyll content of Pteris vittata. Guizhou Agricultural Sciences,2012,40(4):56-58.

[32]TANG Chun-fang. Research on correlations bewteen heavy metal and plant and the regulative role of Polyamine. The DePartment of Enviornmental Science and Engineering of HunanUniversity,2005.

[33]GEI Cai-lin, YANG Xiao-yong,ZHU Hong-xia, et al.Effect of heavy metals stress on catalase of rice leaves and isoenzymes. Acta Agriculturae Nucleatae Sinica,2002,16(4):197-202 